\title{
Frequency of infrapatellar neuropathy post- total knee replacement and arthroscopic surgery in Egyptian patients
}

\author{
Dalia Salah Saif ${ }^{1 *}$ and Mohamed Ahmed Eltabl ${ }^{2}$
}

\begin{abstract}
Background: The infrapatellar branch of the saphenous nerve (IPBSN) contains only sensory fibers that innervate the knee regarding its anteromedial aspect and the anterior-inferior portion of its capsule. IPBSN damage has been recorded as a postoperative complication of surgery about the knee, which is manifested by pain, numbness and reflex sympathetic dystrophy. The incisions made for arthroscopy, medial arthrotomy, and anterior cruciate ligament surgery also, can causes IPBSN damage in about 0.5 to $30 \%$ of cases. We aimed to study the frequency of infrapatellar branches of the saphenous nerve entrapment/ injured in Egyptian patients to find the incidence of its affection in post-operative knee surgeries and to increase the awareness of this condition.

Results: Ninety patients complaining pain at the antero-medial aspect of the knee were collected and divided into 3 groups: G1 included 30 patients with a history of total knee replacement, G2 included 30 patients with a history of knee arthroscopy and $G 3$ included 30 patients with non-specific knee pain. All patients went to clinical, electrophysiological study and laboratory measures.

There was a significant statically differences of sensory nerve conduction study regarding latency and amplitude of infrapatellar nerve between the three groups and significant statically differences of clinical signs among patients of the studied groups regarding Hofmann-Tinel sign and pain provocation test.

Conclusion: The entrapment/injury of IPBSN is an underestimated sometimes unrecognized cause of postoperative knee pain to many clinicians. Awareness of this condition would probably help in managing these cases to decrease post-operative pain and disability as the frequency of infrapatellar neuropathy post total knee replacement was $56.6 \%$ and post arthroscopic surgery was $63.3 \%$ in cohort of Egyptian patients.
\end{abstract}

Keywords: Infrapatellar nerve, Entrapment/injured, Arthroplasty-arthroscopy-tunnels, Sign-sensory conductive study

\section{Background}

The infrapatellar branch of the saphenous nerve (IPBSN) contains only sensory fibers that innervate the knee regarding its anteromedial aspect and the anterior-inferior portion of its capsule. The saphenous nerve gives the

\footnotetext{
* Correspondence: sdalia30@gmail.com

'Physical Medicine, Rheumatology and Rehabilitation Department, Faculty of Medicine, Menoufia University, 18 El Mamoon street-Shebeen El coom,

Menoufia Governorate, Shebin El-Kom, Egypt

Full list of author information is available at the end of the article
}

IPBSN through the adductor hiatus then it pierces the fascia lata and become subcutaneous [1].

One of the often causes of anterior and/or medial knee pain and tightness on the back of the leg above knee is entrapment/injured of the infrapatellar branch of the saphenous nerve which is usually presents with going upstairs and is caused by either compression or irritation of the saphenous nerve at the adductor canal or anywhere along its course. The entrapment/ injured also may be associated with trauma to the nerve either surgical or non-surgical, typically at the

\section{Springer Open}

(c) The Author(s). 2020 Open Access This article is licensed under a Creative Commons Attribution 4.0 International License, which permits use, sharing, adaptation, distribution and reproduction in any medium or format, as long as you give appropriate credit to the original author(s) and the source, provide a link to the Creative Commons licence, and indicate if changes were made. The images or other third party material in this article are included in the article's Creative Commons licence, unless indicated otherwise in a credit line to the material. If material is not included in the article's Creative Commons licence and your intended use is not permitted by statutory regulation or exceeds the permitted use, you will need to obtain permission directly from the copyright holder. To view a copy of this licence, visit http://creativecommons.org/licenses/by/4.0/. 


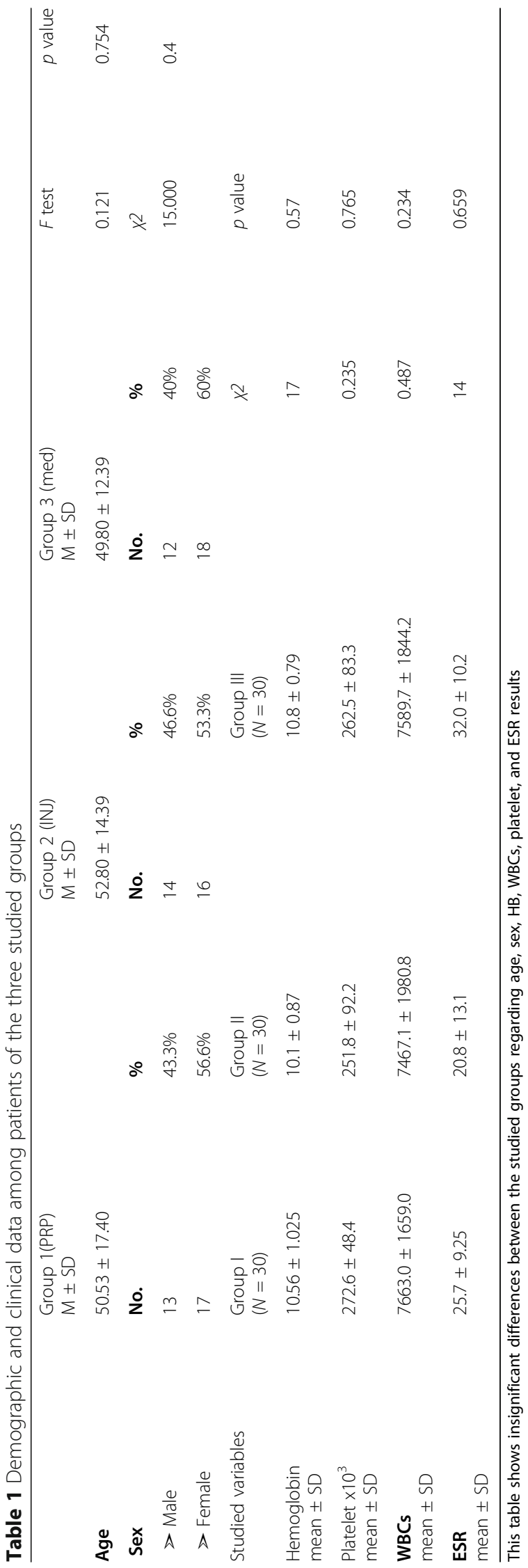


medial or anterior aspect of the knee. The infrapatellar nerve entrapment/injured symptoms are often mistaken for other more frequently encountered disorders affecting this area, such as knee joint osteoarthritis, patello-femoral pain syndrome, medial collateral ligament injuries pes anserine bursitis, and medial meniscus injuries $[2,3]$.

IPBSN entrapment/injured is difficult in diagnosis as it may be mistaken with or mimic a variant of conditions as lumbar radiculopathy, suprapatellar plica, patellofemoral disorders, tibial stress fracture, tear of medial meniscus, pes anserine tendonopathy or bursitis, reflex sympathetic dystrophy osteochondritis dissecans, and nonspecific synovitis [4].

IPBSN damage has been recorded as a postoperative complication of surgery about the knee, which manifested by pain, numbness and reflex sympathetic dystrophy. The incisions made for arthroscopy, medial arthrotomy, and anterior cruciate ligament surgery also, can causes IPBSN damage in about 0.5 to $30 \%$ of cases [5].

In the present article we aimed to study the frequency of infrapatellar branches of the saphenous nerve entrapment/injured in Egyptian patients to find the incidence of its affection in post-operative knee surgeries and to increase the awareness of this condition.

\section{Methods}

The study was approved by ethical committee in faculty of medicine of our institutional University.
An informed written consent was obtained from each patient.

A case-control study includes ninety patients complaining of pain at the antero-medial aspect of the knee were collected from the outpatient clinic of physical medicine, rheumatology and rehabilitation department in the period from a February 2018 to February 2019. Patients of the present study were collected and classified into 3 groups: the first group included 30 patients with a history of total knee replacement, the second group included 30 patients with a history of knee arthroscopy and the third group included 30 patients with non-specific knee pain persistent for more than 3 months with exclusion of local( previous trauma, surgery, fracture, and arthroscopy) and systemic (inflammatory, metabolic and late stage of degenerative arthropathy) causes of knee pain and the procedure performed to patients with this complain after the mentioned duration. The study included both sex. Their age ranged from 49 to 60 years. The presenting study excludes pregnancy, history of underlying metabolic diseases (such as diabetes mellitus, thyroid diseases, and rheumatoid arthritis) which can cause neuropathic pain or musculoskeletal pain in knee region.

All patients were subjected to demographic data recording, history taking, clinical examination including general, local, and neurological examination of

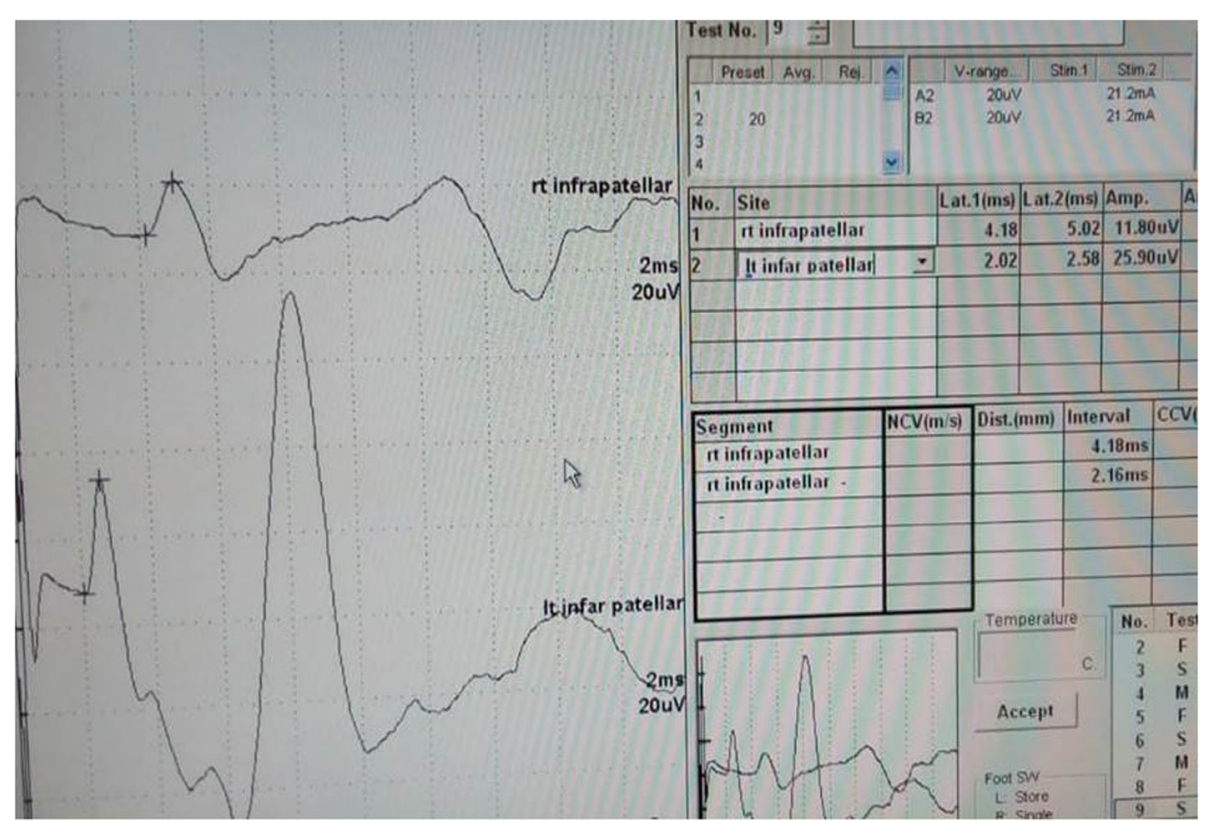

Fig. 1 Electrophysiological parameters of infrapatellar nerve including the peak sensory latency and amplitude, performed in the department of Rheumatology and Rehabilitation by assessment of the sharing rheumatologist using NIHON KOHDEN apparatus 


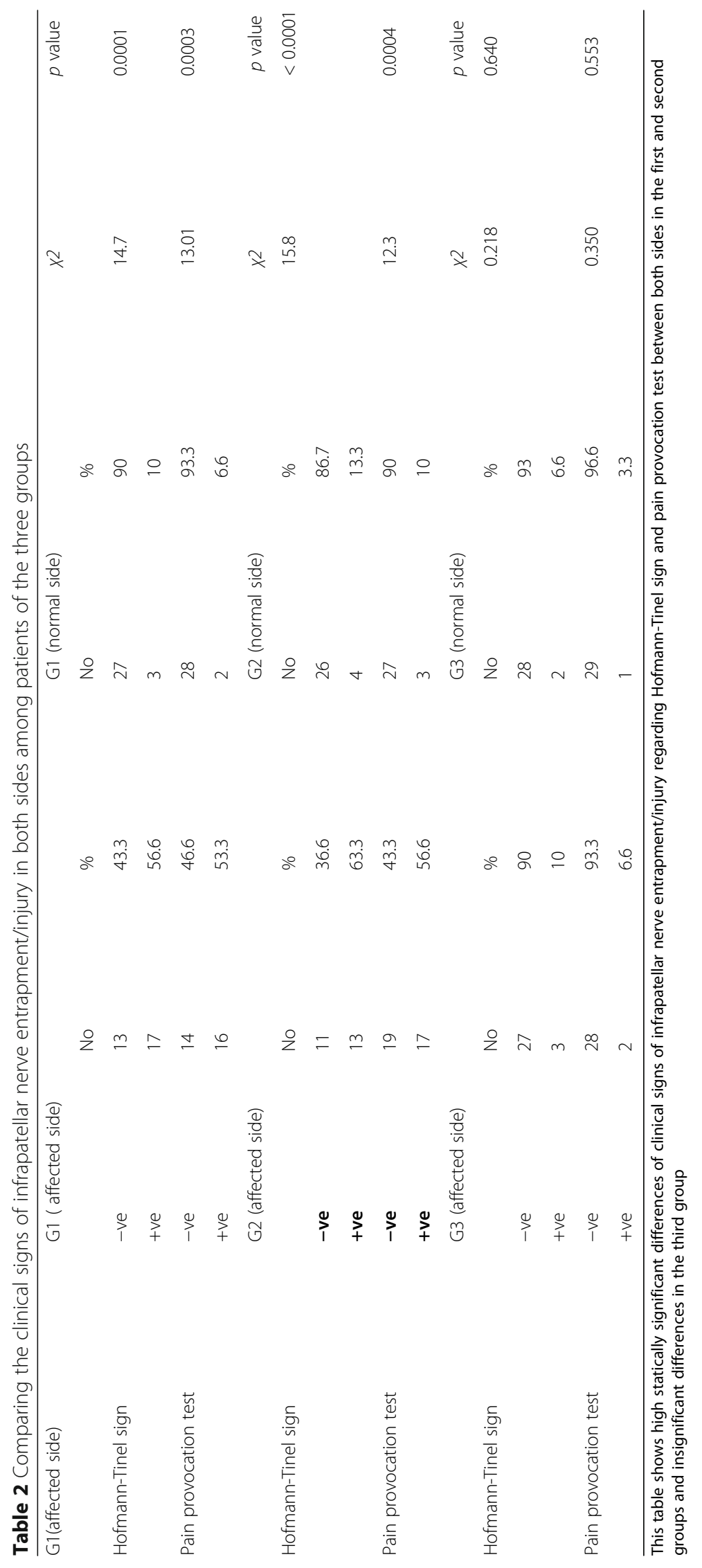




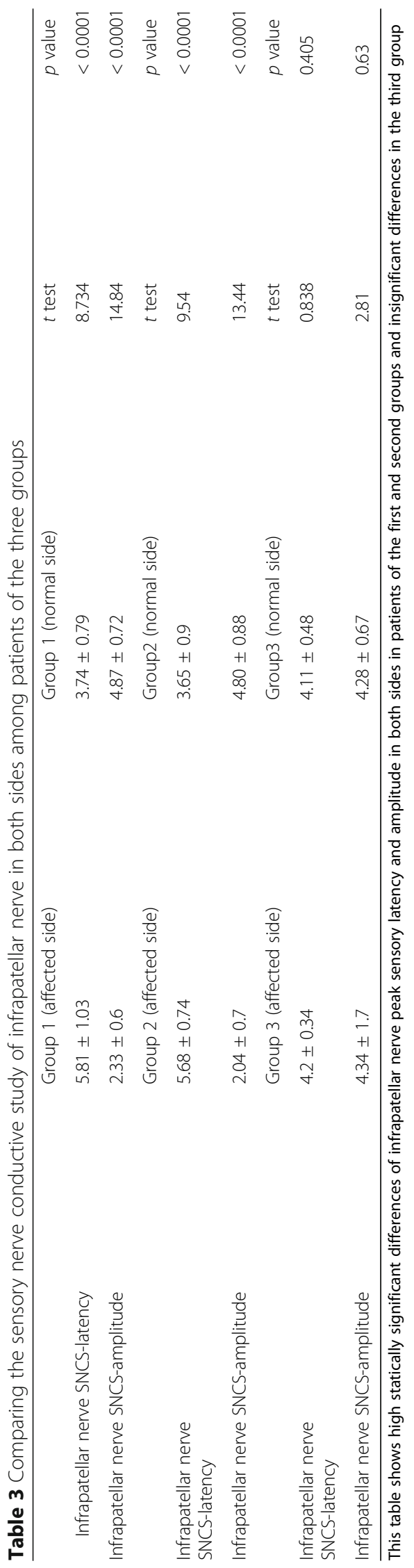




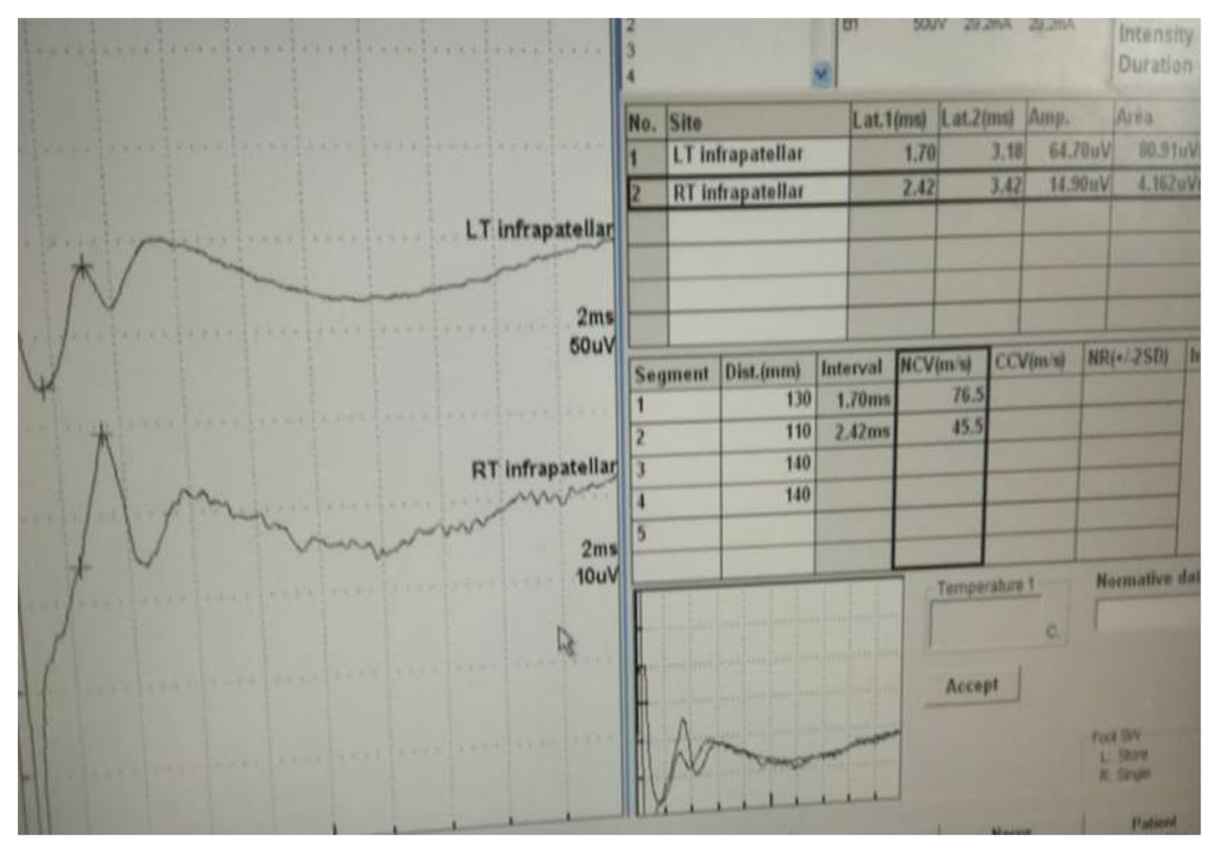

Fig. 2 Electrophysiological parameters of infrapatellar nerve including the peak sensory latency and amplitude, performed in the department of Rheumatology and Rehabilitation by assessment of the sharing rheumatologist using NIHON KOHDEN apparatus

knee, and all have done complete blood count (CBC), erythrocyte sedimentation rate (ESR), C-reactive protein (CRP), and hepatitis $\mathrm{C}$ virus antibody (HCV) to exclude systemic polyneuropathy.

Electrophysiological parameters including the peak latency (PL) and the amplitude of the sensory nerve action potential (SNAP) were measured for all patients using a NIHON KOHDEN apparatus. The study was performed on both sides. Infrapatellar nerve entrapment/injured was defined as peak sensory latency of longer than 4.2 $\mathrm{ms}$, and the amplitude was less than 4.4 uv regarding to Kim and his colleague as they reported in their study the normal parameters of peak sensory latency $(4.11 \pm 0.30$ $\mathrm{ms})$ and amplitude $(4.16 \pm 1.49 \mu \mathrm{V})$ of IPBSN [6], Figs. 1 and 2 .

Recording was performed with patient in a supine position, extended their legs. The recording was done with a 10-min sweeping time, 0.1-0.2 min stimulus duration and $20-30 \mathrm{~mA}$ stimulus intensity, which was the highest intensity without stimulation of the neighboring nerves. Recording at optimum stimulation and recording site was anticipated. Stimulation was conducted on the $\mathrm{X}$-reference line about 5-6 $\mathrm{cm}$ medial to the patella medial

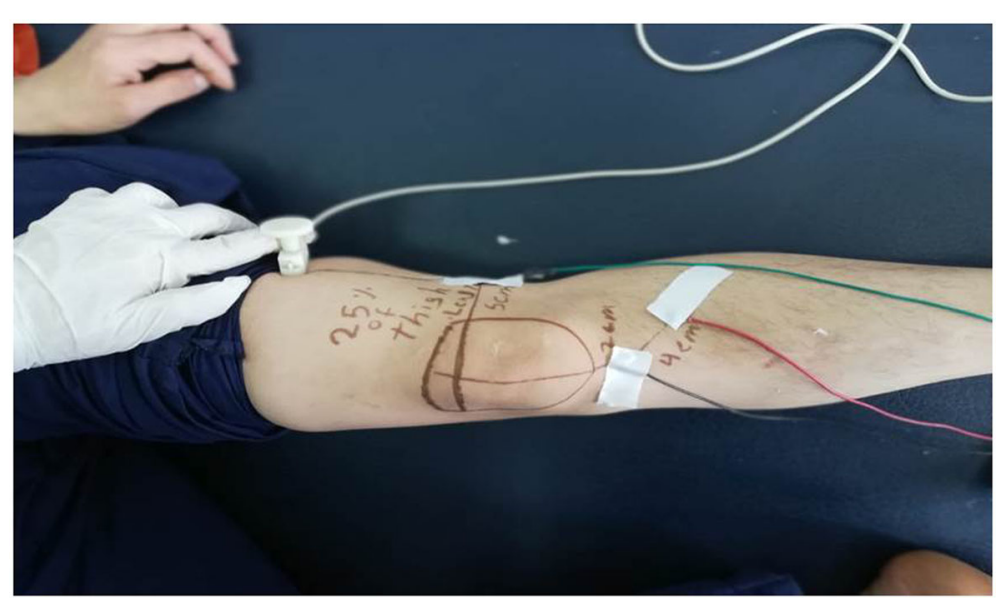

Fig. 3 Technique of NCS of infrapatellar nerve, performed in the department of Rheumatology and Rehabilitation by assessment of the sharing rheumatologist using NIHON KOHDEN apparatus 
Table 4 Clinical signs of infrapatellar nerve entrapment/ injury among patients of the three studied groups in the affected side

\begin{tabular}{|c|c|c|c|c|c|c|c|c|c|}
\hline & & G1 & & $\mathrm{G} 2$ & & G3 & & & $p$ value \\
\hline & & No & $\%$ & No & $\%$ & No & $\%$ & $x^{2}$ & \\
\hline \multirow[t]{4}{*}{ Hofmann-Tinel sign } & -ve & 13 & 43.3 & 11 & 36.6 & 27 & 90 & 0.758 & 0.038 \\
\hline & $+v e$ & 17 & 56.6 & 19 & 63.3 & 3 & 10 & & \\
\hline & & G1 & & $\mathrm{G} 2$ & & G3 & & & $p$ value \\
\hline & & No & $\%$ & No & $\%$ & No & $\%$ & $x^{2}$ & \\
\hline \multirow[t]{2}{*}{ Pain provocation test } & $-v e$ & 14 & 46.6 & 13 & 43.3 & 28 & 93.3 & 0.647 & 0.049 \\
\hline & + ve & 16 & 53.3 & 17 & 56.6 & 2 & 6.6 & & \\
\hline
\end{tabular}

No number, \% percent

This table shows a significant statically differences of clinical signs regarding Hofmann Tinel sign and pain provocation test of infrapatellar nerve entrapment/ injury in the affected side by comparing both first and second groups with the third group while the first and second groups were comparable

tip, and on the $\mathrm{Y}$ - at the lower quarter of the thigh length. Recording electrode was placed 1.5$2.0 \mathrm{~cm}$ below the patella's inferior tip and the reference electrode was positioned $4 \mathrm{~cm}$ distal to the recording electrode regarding to the direction of IPBSN, Fig. 3.

Entrapment/injured of infrapattelar nerve diagnosed clinically by: a sharp pain at the level of the Hunter canal which can be provoked by pressure (Hofmann-Tinel sign). A pain provocation test can be used to determine the presence of a neuropathy of the saphenous nerve as the patient is on the side, the hip is extended and abducted and the knee flexed.

So, we rely on both clinical and electrophysiological study of infrapatellar nerve to diagnose its entrapment/ injured.

SPSS (Social Science Software Statistical Package), version 16, was used, tabulated and analyzed the data obtained on an IBM compatible computer. Two types of statistics were performed: descriptive statistics included percentage (percent), mean, and SD, and analytical statistics included Student's $t$ test, post-hoc test (used to identify significant differences while evaluating three or more groups), $X^{2}$ and ANOVA ( $F$ test used to assess the variation between the groups when the means is greater than the variation of the group's observations). $p$ value was nonsignificant if $p$ value exceeded 0.05 , it is significant if $p$ value was equal or less than 0.05 and was extremely significant if $p$ value exceeded 0.001 [7].

\section{Results}

There was no significant difference in the patients of the studied groups regarding age, sex HB, WBCs, Platelet and ESR results in Table 1.

There were a high statically significant differences of clinical signs of infrapatellar nerve entrapment/ injury regarding Hofmann-Tinel sign and pain provocation test and electrophysiologic study of infrapatellar nerve regarding peak sensory latency and amplitude between the two sides in patients of the first and

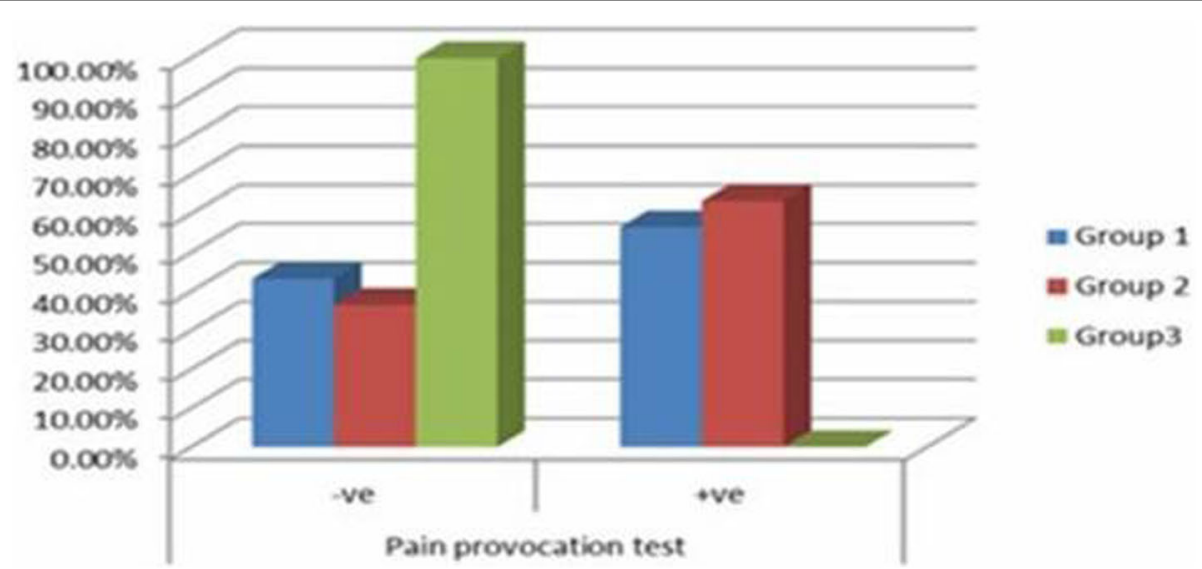

Fig. 4 Our clinical study revealed a significant statically differences of clinical signs regarding pain provocation test of infrapatellar nerve entrapment/injury in the affected side by comparing both first and second groups with the third group while the first and second groups were comparable 
Table 5 Sensory nerve conductive study of infrapatellar nerve among patients of the three studied groups in the affected side

\begin{tabular}{|c|c|c|c|c|c|c|}
\hline & Group 1 & Group 2 & Group 3 & $F$ test & $p$ value & LSD \\
\hline \multirow{3}{*}{$\begin{array}{l}\text { Infrapatellar nerve } \\
\text { SNCS-latency }\end{array}$} & \multirow[t]{3}{*}{$5.81 \pm 1.03$} & \multirow[t]{3}{*}{$5.68 \pm 0.74$} & \multirow[t]{3}{*}{$4.2 \pm 0.34$} & \multirow[t]{3}{*}{47.132} & \multirow[t]{3}{*}{0.001} & $\mathrm{p} 1=0.78$ \\
\hline & & & & & & $\mathrm{p} 2=0.05$ \\
\hline & & & & & & $\mathrm{p} 3=0.04$ \\
\hline \multirow{3}{*}{$\begin{array}{l}\text { Infrapatellar nerve } \\
\text { SNCS-amplitude }\end{array}$} & \multirow[t]{3}{*}{$2.33 \pm 0.6$} & \multirow[t]{3}{*}{$2.04 \pm 0.7$} & \multirow[t]{3}{*}{$4.34 \pm 1.7$} & \multirow[t]{3}{*}{55.245} & \multirow[t]{3}{*}{0.001} & $\mathrm{p} 1=0.65$ \\
\hline & & & & & & $\mathrm{p} 2=0.03$ \\
\hline & & & & & & $\mathrm{p} 3=0.02$ \\
\hline
\end{tabular}

LSD least significant differences, SNCS sensory nerve conductive study

This table shows a significant statically differences of sensory nerve conduction study regarding latency and amplitude of infrapatellar nerve in the affected side by comparing both first and second groups with the third group while the first and second groups were comparable

second groups and insignificant differences in the third group in Tables 2 and 3.

There was a significant statically differences of clinical signs of infrapatellar nerve entrapment/ injury in the affected side regarding Hofmann Tinel sign and pain provocation test by comparing both first and second groups with the third group while the first and second groups were comparable in Table 4, Fig. 4.

There was a significant statically differences of sensory nerve conduction study regarding latency and amplitude of infrapatellar nerve in the affected side by comparing both first and second groups with the third group while the first and second groups were comparable in Table 5, Fig. 5.

Among the 30 patients of the first group with total knee replacement, about 17 patients were diagnosed as infrapatellar nerve entrapment/injured regarding both clinical and electrophysiological findings with a rate of $56.6 \%$, and among the 30 patients of the second group with arthroscopy about 19 patients were diagnosed as infrapatellar nerve entrapment/injured with a rate of $63.3 \%$. However, among the 30 patients of the third group who are presented by variant grades of knee pain there was no patient diagnosed as infrapatellar nerve entrapment/injured regarding electrophysiological study in spite the presence of clinical signs in about 3 patients but without electrophysiological abnormality in Table 6, Fig. 6.

\section{Discussion}

Our results were consistent with Sundaram and his colleague [8] as they demonstrated through their clinical study that about $55 \%$ of patients following Total Knee Arthroplasty complained altered sensation around the knee at the distribution of infrapattelar nerve during a follow-up period of 2.7 years.

Jacob and his team also [9] reported that the overall incidence of infrapatellar nerve injury following total knee arthroplasty was $79 \%$ of patients of their study group.

In the same way, Henningsen study [10] revealed that about $84 \%$ of the patients receiving total knee

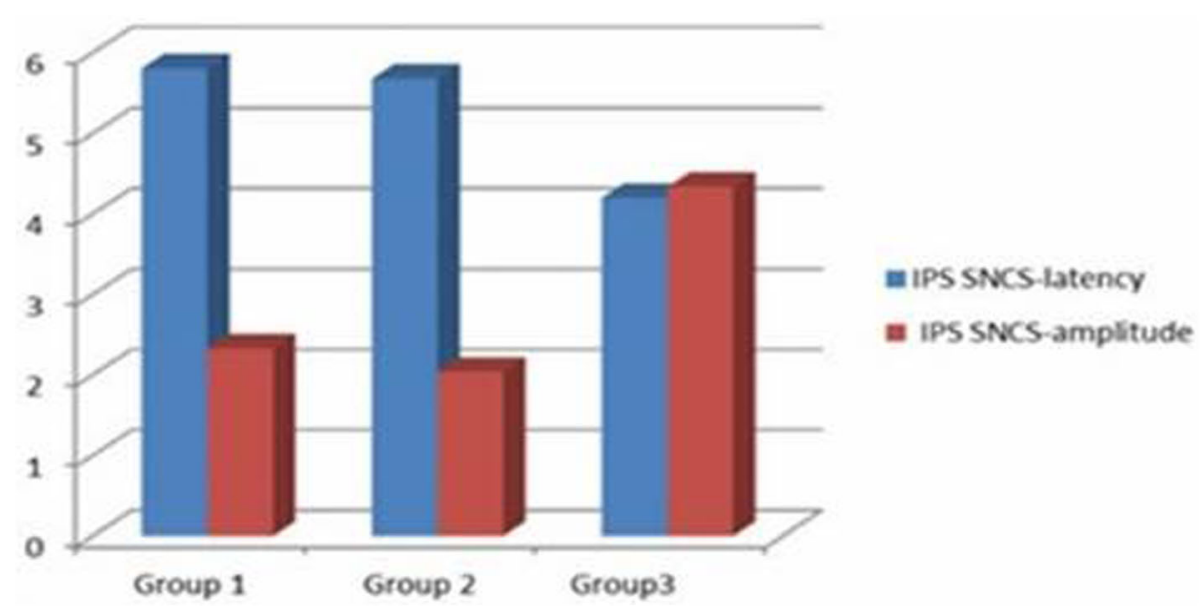

Fig. 5 Our electrophysiological study revealed a significant statically differences of sensory nerve conduction study regarding latency and amplitude of infrapatellar nerve in the affected side by comparing both first and second groups with the third group while the first and second groups were comparable 
Table 6 Frequency of infrapatellar nerve entrapment among patients of the three studied groups

\begin{tabular}{|c|c|c|c|c|c|c|c|c|}
\hline & \multicolumn{2}{|c|}{ Group 1} & \multicolumn{2}{|c|}{ Group 2} & \multicolumn{2}{|c|}{ Group 3} & \multirow{2}{*}{$\frac{x^{2}}{0.758}$} & \multirow{2}{*}{$\begin{array}{l}p \text { value } \\
0.03\end{array}$} \\
\hline \multirow{2}{*}{$\begin{array}{l}\text { Frequency of infrapatellar } \\
\text { nerve entrapment }\end{array}$} & No & $\%$ & No & $\%$ & No & $\%$ & & \\
\hline & 17 & 56.6 & 19 & 63.3 & 0 & 0 & & \\
\hline
\end{tabular}

This table shows the frequency of infrapatellar nerve entrapment among patients of the three studied groups.

arthroplasty had signs of entrapment/injured to the infrapatellar branch of the saphenous nerve in the operated leg.

Mistry and his colleague also reported that the sensory changes caused by damage to the infrapatellar branch of the saphenous nerve during total knee joint arthroplasty is a common occurrence and can interfere with patient satisfaction [11].

Our results were consistent also with Sanders et al. [12] as they reported that about $74 \%$ of patients post arthroscopic surgery developed infrapattelar nerve entrapment/injured.

Kartus and his colleague [13] also documented that the iatrogenic injury of infrapatellar nerve post knee arthroscopy has been found in about 12 to $84 \%$ of cases.

In the same way, Mochida and Kikuchi [14] reported that the sensory disturbances in the region where the infrapatellar branch is distributed in patients after arthroscopic knee surgery recorded an incidence rate of $22.2 \%$ that can be reduced by clarifying the distribution of the infrapatellar nerve branch regarding to palpable landmarks.

Figueroa and Portland [15, 16] also reported that the sensory disturbances in the distribution of infrapatellar nerve in patients who undergo arthroscopic surgery has been reported as $0.06-77 \%$ incidence rate.
Jameson and his team [17] reported that the incidence of infrapattelar nerve entrapment/injured in patients post arthroscopic surgery was $5 \%$.

On the other line, Tifford and his team [18] reported that injury to the infrapatellar branches of the saphenous nerve is not an uncommon occurrence after ACL reconstruction, meniscus repair, or even routine diagnostic arthroscopy

Our results were consistent with Hosahalli [3] clinical study as the reported that the incidence of infrapattelar nerve entrapment/injured among patients with nonspecific knee pain accounts for $<1 \%$ of adults presenting with lower extremity pain [3].

We recommended carrying out more extensive studies on the infrapatellar branch of the saphenous nerve using a greater variance in age and larger sample size to measure the incidence and the prevalence of its affection among cohort of Egyptian patients that could help in the treatment of this condition.

\section{Conclusion}

The entrapment/injury of IPBSN is an underestimated sometimes unrecognized cause of post-operative knee pain to many clinicians. Awareness of this condition would probably help in managing these cases to decrease post-operative pain and disability as the frequency of infrapatellar neuropathy post total knee replacement was

\section{Incidence of IPS entrapment}

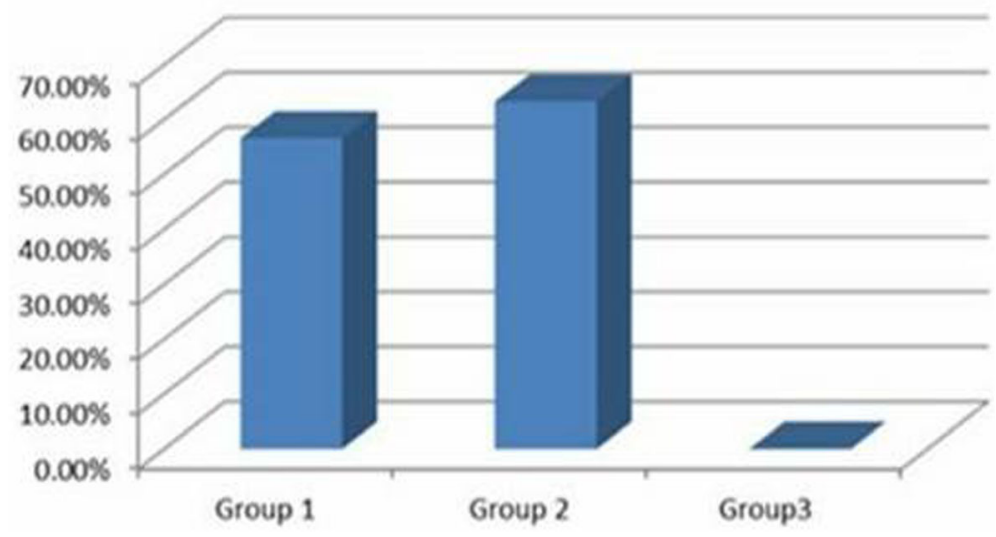

Fig. 6 Our clinical and electrophysiological study revealed the incidence of infrapatellar neuropathy among patients of the study groups as $56 \%$ in the first group, $63 \%$ of the second group and $0 \%$ in the third group 
$56.6 \%$ and post arthroscopic surgery was $63.3 \%$ in cohort of Egyptian patients.

\section{Abbreviations}

IPBSN: Infrapatellar branch of the saphenous nerve; CBC: Complete blood count; ESR: Erythrocyte sedimentation rate; CRP: C-reactive protein; HCV: Hepatitis C virus; PL: Peak latency; SNAP: Sensory nerve action potential; CMAP: Compound muscle action potential; SPSS: Statistical package for the social science software; SD: Standard deviation; LSD: Least significant differences

\section{Acknowledgements}

Not applicable

\section{Authors' contributions}

DSS gave idea and collected the patients' data, analyze them and performed the electrodiagnostic study. MAE put study design and followed the patients. The author(s) read and approved the final manuscript.

\section{Funding}

This study had no funding from any resource.

\section{Availability of data and materials}

The datasets used and/or analyzed during the current study are available from the corresponding author on reasonable request.

\section{Ethics approval and consent to participate}

This study was approved by the Research Ethics Committee of the Faculty of Medicine at Menoufia University in Egypt in February 2018; reference number of approval 19719NEUS6. All patients included in this study gave written informed consent to participate in this research. The study did not include patient less than 16 years old or unconscious patients.

\section{Consent for publication}

All patients included in this research gave a written informed consent to publish the data contained within this study. The study not includes patient less than 16 years old or unconscious patients.

\section{Competing interests}

The authors declare that they have no competing interests.

\section{Author details}

${ }^{1}$ Physical Medicine, Rheumatology and Rehabilitation Department, Faculty of Medicine, Menoufia University, 18 El Mamoon street-Shebeen El coom, Menoufia Governorate, Shebin El-Kom, Egypt. ${ }^{2}$ Neurosurgery Department, Faculty of Medicine, Menoufia University, Shebin El-Kom, Egypt.

Received: 25 March 2020 Accepted: 31 May 2020

Published online: 01 October 2020

\section{References}

1. Grabowski R, Gobbi A, Zabierek S., , and Domzalski M. E. Nonspecific chronic anteromedial knee pain neuroma as a cause of infrapatellar pain syndrome: case study and literature review. Orthop J Sports Med. 2018; 6(1): 23-25.

2. Trescot AM, Brown MN, Karl HW (2013) Infrapatellar saphenous neuralgia: diagnosis and treatment. Pain Physician. 16(3):315-324

3. Hosahalli G, Sierakowski A, Venkatramani H, Sabapathy SR (2017) Entrapment neuropathy of the infrapatellar branch of the saphenous nerve: treated by partial division of sartorius. Indian J Orthop. 51(4):474-476

4. Jason Porr, , Karen Chrobak, Brad Muir. Entrapment of the saphenous nerve at the adductor canal affecting the infrapatellar branch - a report on two cases. J Can Chiropr Assoc. 2013; 57(4): 341-349.

5. Tifford CD, Spero L, Luke T, Plancher KD (2000) The relationship of the infrapatellar branches of the saphenous nerve to arthroscopy portals and incisions for anterior cruciate ligament surgery. An anatomic study. Am. J. Sports Med. 28:562-567

6. Kim K-t, Kim Y-k, Yoon JR, Ko Y, Chung ME (2018) Reference value for infrapatellar branch of saphenous nerve conduction study: cadaveric and clinical study. Ann Rehabil Med 42(2):321-328
7. SPSS Programming and Data Management. A guide for SPSS and SAS Users. 2007. Fourth Edition, SPSS Inc., USA.Chicago, 3.

8. Sundaram RO, Ramakrishnan M, Harvey RA, Parkinson RW (2007) Comparison of scars and resulting hypoaesthesia between the medial parapatellar and midline skin incision in total knee arthroplasty. Knee 14: 375-378

9. Jacob AK, Mantilla CB, Sviggum HP, Schroeder DR, Pagnano MW, Hebl JR (2011) Perioperative nerve injury after total knee arthroplasty: regional anesthesia risk during a 20-year cohort study. Anesthesiology 114:311-317

10. Henningsen $H$, Jæger $P$, Hilsted KL, Dahl JB (2013) Prevalence of saphenous nerve injury after adductor-canal-blockade in patients receiving total knee arthroplasty. Acta Anaesthesiol Scand 57:112-117

11. Mistry D, O'Meeghan C (2005) Fate of the infrapattelar branch of the saphenous nerve post total knee arthroplasty. ANZ J. Surg. 75:822-824

12. Sanders B, Rolf R, McClelland W, Xerogeanes J (2007) Prevalence of saphenous nerve Injury after autogenous hamstring harvest: An anatomic and clinical study of sartorial branch injury. Arthroscopy 23:956-963

13. Kartus J, Magnusson L, Stener S, Brandsson S, Eriksson Bl, Karlsson J (1999) Complications following arthroscopic anterior cruciate ligament reconstruction. A 2-5 year follow-up of 604 patients with special emphasis on anterior knee pain. Knee Surg Sports Traumatol Arthrosc. 7:2-8

14. Mochida H, Kikuchi S (1995) Injury to infrapatellar branch of saphenous nerve in arthroscopic knee surgery. Clin Orthop Relat Res. 320:88-94

15. Figueroa D, Calvo R, Vaisman A, Campero M, Moraga C (2008) Injury to the infrapatellar branch of the saphenous nerve in $A C L$ reconstruction with the hamstrings technique: clinical and electrophysiological study. Knee. 15(5): 360-363

16. Portland GH, Martin D, Keene G, Menz T (2005) Injury to the infrapatellar branch of the saphenous nerve in anterior cruciate ligament reconstruction: comparison of horizontal versus vertical harvest site incisions. Arthroscopy. 21(3):281-285

17. Jameson S, Emmerson K (2007) Altered sensation over the lower leg following hamstring graft anterior cruciate ligament reconstruction with transverse femoral fixation. Knee 14:314-320

18. Tifford CD, Spero L, Luke T, Plancher KD (2000) The relationship of the infrapatellar branches of the saphenous nerve to arthroscopy portals and incisions for anterior cruciate ligament surgery: an anatomic study. Am J Sports Med 28: 4(2):562-567

\section{Publisher's Note}

Springer Nature remains neutral with regard to jurisdictional claims in published maps and institutional affiliations.

\section{Submit your manuscript to a SpringerOpen ${ }^{\circ}$ journal and benefit from:}

- Convenient online submission

- Rigorous peer review

- Open access: articles freely available online

- High visibility within the field

- Retaining the copyright to your article

Submit your next manuscript at $>$ springeropen.com 